\title{
A REMINISCÊNCIA EM ARTHUR BISPO DO ROSÁRIO
}

REMINISCENCE IN ARTHURBISPO DO ROSARIO

Ana de Almeida

Arte-Educadora

Resumo: A produção de Arthur Bispo do Rosario é singular em suas complexidades. Este artigo investiga resquícios de uma cultura nordestina-cristã/ibero-brasileira que tenha formado a base espíritovisual - a cultura popular sergipana e a religiosidade católica - que parece compor a materialidade dos seus trabalhos. Se fez necessário enaltecer as questões biográficas referentes à vida de Bispo, desvendando a personalidade que o mesmo incute em sua produção, quando extrapola a esquizofrenia diagnosticada e mescla a memória visual da infância com uma missão delegada por vozes dentro de sua mente, para então cumpri-la até o dia de sua passagem..

Palavras-Chave: Arthur Bispo do Rosario, Cultura popular, Loucura, Arte, Crítica.

Abstract: Arthur Bispo do Rosario's production is unique in its complexities. This article investigates remnants of a Northeastern-Christian / Ibero-Brazilian culture that has formed the spirit-visual base - popular culture in Sergipe and Catholic religiosity - that seems to compose the materiality of his works. It was necessary to praise the biographical questions concerning Bispo's life, unveiling the personality that Bispo incites in his production, when he extrapolates the diagnosed schizophrenia and mixed the visual memory of childhood with a mission delegated by voices within the your mind, to fulfill it until the day of its passage.

Keywords: Arthur Bispo do Rosario, Madness, Popular culture, Art, Criticism. 


\section{Introdução}

Platão especifica propostas e conceitos possíveis da palavra poíesis em algumas de suas obras dentro da perspectiva filosófica sobre arte: a Estética. Em cada texto, o filósofo atribuiu uma característica singular ao vocábulo. Entretanto, é em O Sofista que a terminologia se alude ao que podemos encontrar no legado artístico de Arthur Bispo do Rosario:

O conceito de poíesis está explicitado nas relações entre produções divinas e produções humanas, sendo que as divinas são divididas como arte da própria coisa e sua imagem, ao passo que a humana, além dessa divisão, produz imitação².

Se divino e humano se mesclam neste conceito, Bispo se entremearia na mescla de ser humano e ser divino - obviamente de forma onírica, segundo sua própria fala uma espécie de meta-divindade. Portanto, o inventário do mundo produzido por ele se caracterizaria como o resultado desse conjunto insano. Em 1938, Bispo se apresentou para os frades no Mosteiro de São Bento, no Rio de Janeiro, como Jesus: a própria divindade. A humanidade, por sua vez, Ihe é apresentada quando, minutos depois, foi

1 Optei por utilizar o sobrenome Rosario sem acento, que é a maneira à qual a biografa Luciano Hidalgo recorre. Uma vez que o registro de batismo na Igreja Matriz de Nossa Senhora da Saúde, em Japaratuba, traz a seguinte inscrição: "Aos 5 de outubro de 1909 batizei solenemente Arthur, com 3 meses, legítimo de Claudino Bispo do Rosário e Blandina Francisca de Jesus" (HIDALGO, Luciana. Arthur Bispo do Rosário: O Senhor do Labirinto. Edição Revista. Rio de Janeiro: Editora Rocco, 2011, p. 30). Respeitei o uso com acento (Rosário) quando outros autores o fizeram.

2 NOVELLO, Maria. Teoria da Arte em Platão: O Conceito de Poíesis. In: 6a Mostra Acadêmica UNIMEP, 2008, p. 2.

3 Arthur Bispo do Rosário é internado aos 29 anos no Hospital Nacional dos Alienados em 24 de dezembro de 1938. Foi transferido, em 25 de janeiro de 1939, para a Colônia Juliano Moreira em Jacarepaguá. Entre idas e vindas, permanece na Colônia até sua morte, em 5 de julho de 1989, de infarto do miocárdio e arteriosclerose. encaminhado ao Hospital Nacional dos Alienados. Outro humano the atribuiu o diagnóstico de esquizofrênico-paranoide quando percebeu seu discurso "demasiadamente divino".

Permanece em seu quadro, realizando trabalhos manuais criados por ele, preservando sua personalidade dentro da instituição, através desse meio de defesa desenvolvido pelo próprio. É o único com tal característica, destacando-se dos demais. ${ }^{4}$

Há ainda o registro da recusa em fazer uso da medicação psiquiátrica, uma vez que Bispo, de forma alguma, achava que necessitaria de tal intervenção: "[tenho] em minha ficha como esquizofrênico-paranóide. É erro!” ${ }^{5}$ Bispo sabia muito bem que os efeitos nocivos dos medicamentos em seu organismo o atrapalhariam na execução de sua missão. Assim, destacando-se dos demais, organizava o mundo em miniatura, sua produção; e reorganizava as diretrizes no manicômio ${ }^{6}$, seu lar.

Bispo representou o seu complexo mundo nos respectivos trabalhos. Mesclou o ser humano, e seu extremo sofrimento psíquico, ao ser divino, e sua pseudo-onisciência?. Assim, deveria recriar tudo o que via, ouvia, lia e sentia, mas provavelmente a memória de um Arthur menino (o garoto sergipano, antes de se alistar ${ }^{8}$

4 MORAIS, Frederico. Arte Além da Loucura. [org. e prefécio Flávia Corpas) 1. Ed. Rio de Janeiro: NAU: Livre Galeria, 2013, p. 58.

5 Ibid., p. 59.

6 Bispo tinha privilégios como paciente: com livre trânsito entre as alas, intimidade com os funcionários, ocupou dez celas para abrigar sua missão e tornou-se o Xerife do PaviIhão Ulisses Viana, considerado o mais perigoso da Colônia Juliano Moreira.

7 As vozes exigiam que Bispo conhecesse o que pudesse, para cumprir seu destino: "Para confirmar sua existência, afirmar sua identidade, Bispo do Rosário precisou também provar a existência de tudo o mais que existia no mundo: seu passado - de onde veio e como veio - e seu futuro - a missão que lhe foi dado cumprir." [MORAIS, op. cit., p. 66] 8 "Arthur Bispo do Rosário recolheu-se ao quartel central do 
na Marinha de Guerra em 1926) tenha sido responsável pelo maior impacto visual de toda sua produção.

Bispo subverteu a realidade dura de uma instituição manicomial, quando resistiu aos medicamentos, escapou da eletroculsoterapia ${ }^{9}$ e sobreviveu a era da lobotomia ${ }^{10}$. Confirmou sua existência e afirmou sua identidade através das obras produzidas: união de seu passado (sua origem, e por consequência, sua memória) e seu futuro (sua "vinda", e por consequência, sua missão). A estranha soma da lembrança de uma infância inserida na cultura japaratubense e um delírio crônico com obsessão em produzir, tenha resultado nesse singular fenômeno que atendia pelo nome de Arthur Bispo do Rosario.

\section{A memória na missão}

Ao desembarcar no Rio, o sergipano trouxe consigo reminiscências da cultura de Japaratuba, cidadezinha a cinquenta e quatro quilômetros da capital Aracajú. Bispo, nascido em 1909, presenciou o sincretismo religioso do leste sergipano. É notório que seu repertório visual tenha bebido da fonte do cristianismo ibérico - "o qual identifica proporção com a beleza, e equivale a uma compreensão do mundo como um todo, criado [e] organizado" ${ }^{11}$ - combinado

corpo de Marinheiros Nacionais Villegaigon [em 30/3/1926], onde se alistou pelo prazo de nove anos [...] Por mau comportamento recebeu inúmeras punições [...] foi excluído da Marinha em 8/6/1933 por indisciplina." [MORAIS, op. cit., p. 33]

9 Também conhecido por eletrochoques, é um tratamento psiquiátrico que consiste em provocar alterações no cérebro através de corrente elétrica de alta voltagem sobre a região temporal. Foi utilizado nos manicômios em livre demanda a fim de causar uma indução de crise convulsiva. A técnica, hoje é utilizada sob restrita prescrição médica para tratamentos de patologias mentais agudas.

10 Cirurgia, a qual no passado foi utilizada em pacientes psiquiátricos, que consistia em seccionar as vias que ligam as regiões pré-frontais do cérebro.

11 BARRETO FILHO, Waldir de Mello. A margem da poética. com elementos presente em rituais religiosos de origem africana e indígena.

São Gonçalo, Cacumbi, Reisado, Maracatu, Festa de Reis e Taieiras são manifestações populares da cultura religiosa do Sergipe. Quase todas essas festas sincréticas supracitadas seguem uma matriz espiritual católica - herança do colonialismo francês e holandês no nordeste brasileiro - com expressivos elementos da cultura afro-indígena e de rituais profanos ${ }^{12}$. Por consequência, nelas existem a proporção estética referente à visualidade: ordenação, classificação e seriação, assim como, a temática que expressa a luta entre o bem e o mal. Talvez este embate seja o primeiro indício da relação entre os trabalhos de Bispo e a cultura religiosa sergipana: a produção em extrema harmonia ao rigor visual versus o constante conflito interno contra as vozes que escutava e o obrigava a produzir incansavelmente, o seu mal particular.

Bispo pareceu transitar racionalmente em três territórios culturais presentes em sua memória: a tradição popular nordestina, a marinha de guerra e os fundamentos bíblicos. Entretanto é no embasamento visual - assim como a materialidade e a metodologia técnica - deste primeiro território que, possivelmente, encontramos maiores ressonâncias na produção do sergipano. Neste primeiro campo, a reminiscência da Festa de Reis que acontece na vila de Laranjeiras apareceria vívida em alguns trabalhos de seu legado. Sua influência aos fardões seria um simbolismo presente "nas batalhas entre mouros e capitães-de-marinha da Chegança" ${ }^{13}$, que é o primeiro ato da Festa de Reis. Os foliões da cidade se vestem em trajes militares (marinheiros e capitães) e encenam o aportar em

Vitória: UFES, 2015, p. 16.

12 Id.

13 Id. 


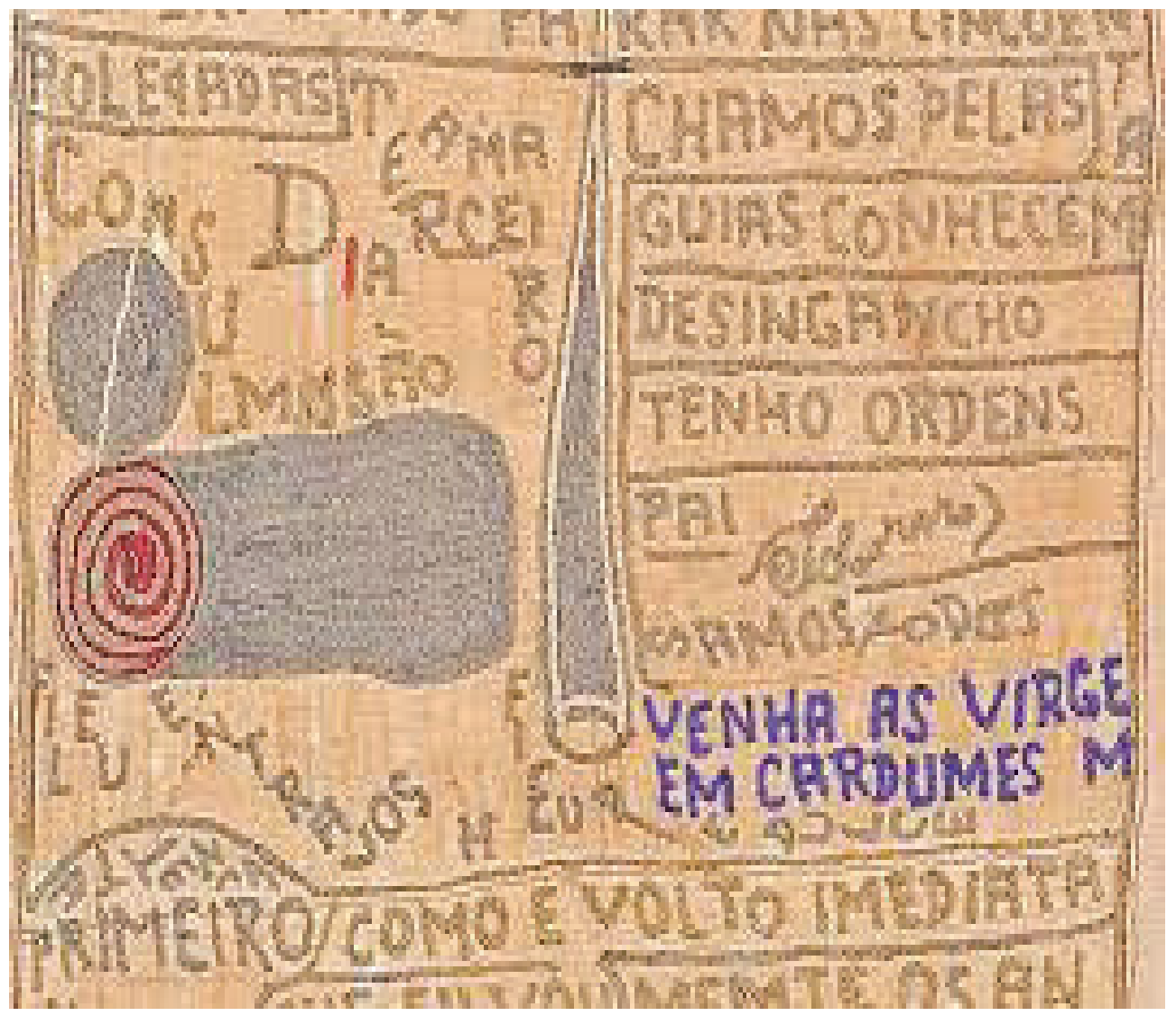

Figura 2. Arthur Bispo do Rosário, VENHA AS VIRGEM EM CARDUMES (detalhe), madeira, tecido, metal, linha e plástico, s/d, s/ data. Fonte: premiopipa.com

fa do Bispo, se atenta a este detalhe: "ao longo de décadas, o povoado católico do Sergipe perpetuou a tradição do bordado, tornando-se um dos pólos de produção e exportação dessa arte na região" ${ }^{18}$. Se a intimidade de Bispo com linhas e agulhas se liga aos resquícios desse artesanato típico do Nordeste, foi em alto mar que ele descobriria que "desde o tempo das velas, a costura e o bordado eram também passatempos tradicionais" ${ }^{19}$.

A tradição de Taieras que acontece na vila de Laranjeiras, provavelmente também se fez presente na memória de Bispo. Nesta festividade

18 HIDALGO, op. cit., p.123.

19 BARRETO FILHO, op. cit., p. 16. em questão, os foliões convocam para desfilar pelas ruas da comunidade as moças virgens da vila - trajando vestidos e chapéus coloridos. Como tradição, uma rainha é empossada à coroa de prata de Nossa Senhora do Rosário: uma virgem - também aludida por Bispo em sua extrema obsessão pela pureza feminina [Fig. 3]. Logo, o sergipano evocaria outro elemento constitutivo da memória, os "personagens": virgens, que desfilam sua pureza no festejo de Taieiras; tal como, marinheiros, representados na solenidade da Chegança e foliões, com vestimentas coloridas e chapéus de palha [Fig. 4], foram prováveis figuras eternizadas por Bispo através da confecção de seus bordados e na construção de trajes e estandartes. 


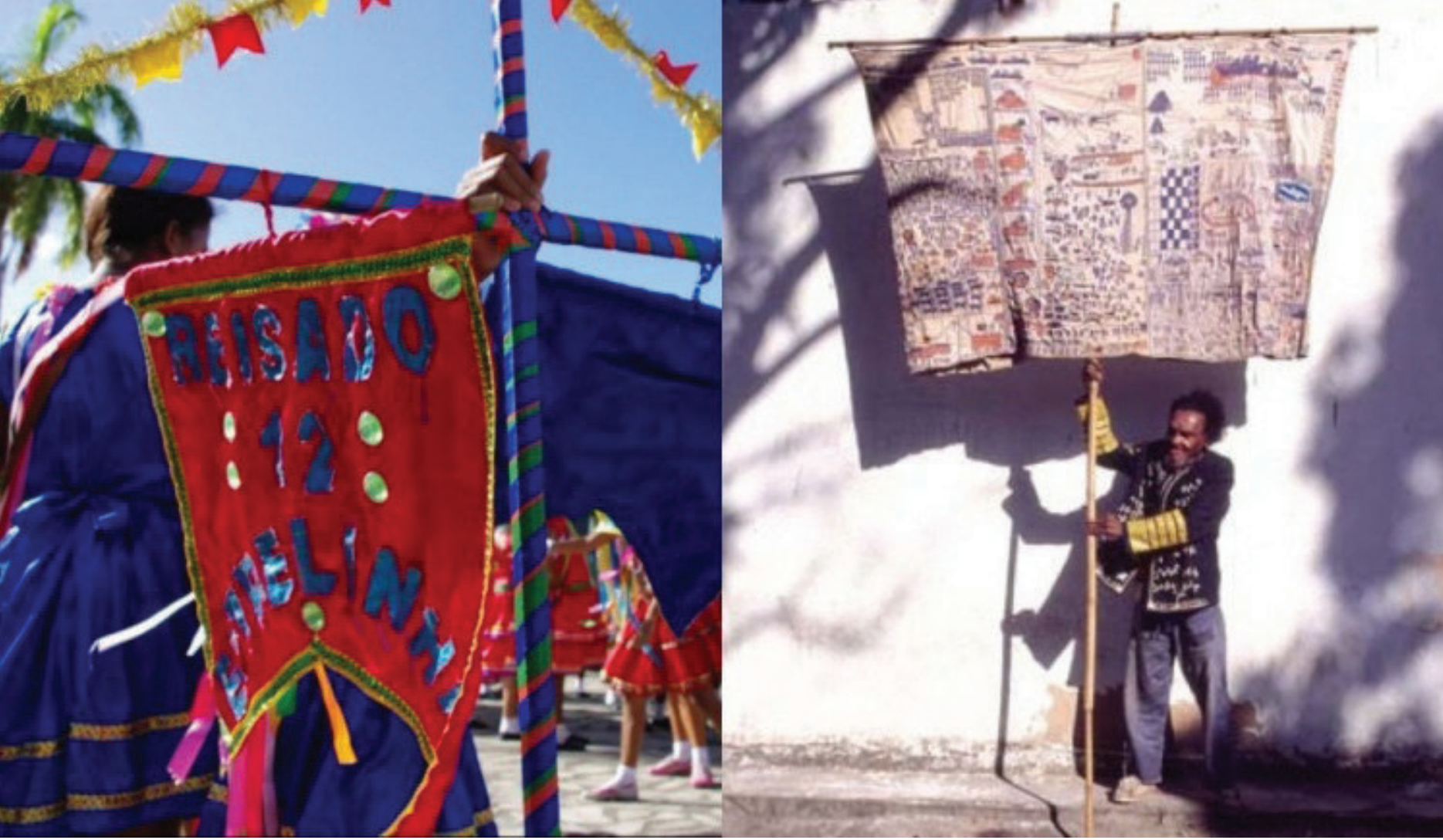

ria todo o significado místico nos ombros de seu autor e foi - pendurado em um cabide -, realocado como uma instalação artística. O Manto em Bispo, semelhante ao manto do Caboclo de Lança, teria por função destacar o ser humano que o traja. Além da função essencial: "preparar e distinguir seu usuário na entrada do céu” ${ }^{24}$, o Manto seria a forma de ser reconhecido como o escolhido de Deus.

"A memória é equivalente à vida, o esquecimento, à morte. Para salvar tudo, haveria que recordar de tudo" ${ }^{25}$. As ligações entre memória e delírio fazem do legado artístico de Bispo algo tão único e complexo. Seu processo transcendia a criação de um artista, pois possuía um tempo limitado para representar a Criação divina.

24 BARRETO FILHO, op. cit., p. 17. $25 \mathrm{lbid}$., p. 18.
Em vida, Bispo interpelava quem lhe visitava com uma pergunta: "Você enxerga a cor da minha aura?" 26 Irônico é pensar sobre significado de "aura" em arte contemporânea. Para Walter Benjamin, a reprodutibilidade na arte extinguia qualquer faísca de aura que a obra de arte poderia possuir ${ }^{27}$. Benjamin explanava a partir do conceito de aura que remetia a "aparição única de uma coisa distante, por mais perto que esteja” ${ }^{28}$, em uma investida de exaltar a singularidade da obra de arte sob o viés único, tradicional e autêntico. Bispo, muito provavelmente sob o delírio que o identificava como divindade, procurava constatar a aura dos visitantes

26 HIDALGO, op. cit., p. 80

27 BENJAMIN, Walter. A obra de arte na época de sua reprodutibilidade técnica. In: ADORNO et al. Teoria da Cultura de massa. Tradução: Carlos Nelson Coutinho. São Paulo: Paz e Terra, 2000, p. 221-254.

28 Ibid., p. 226
Figura 4. À esquerda, Festa do Reisado, s/d; à direita, Walter Firmo, Bispo e seu estandarte, fotografia, 1985. Fonte: istoesergipe. com. 
para elevar o ser humano comum a um status sobre-humano, sublime, celeste.

Sobre sua produção, Bispo não reproduzia, ele representava para apresentar a Deus. Com os mais diversos materiais efêmeros construía um valor místico - paradoxalmente, muito semelhante ao valor de culto que Benjamin também conceituou ${ }^{29}$. Arthur Danto afirma em Após o fim da arte, que a arte contemporânea passou a valorizar elementos que são mais híbridos do que puros, contaminados ao invés de limpos ${ }^{30}$. Tudo isso poderia ser encontrado na produção de Bispo: contaminação e hibridismo para representar a complexidade do mundo.

Sua missão o convocou a relembrar tudo o que já conheceu em vida e reproduzi-lo, recriar o mundo que existia apenas em sua mente. Traços de memória, de leitura, de estudo, ao que parece, compõem o repertório vasto de aproximadamente oitocentos trabalhos, que como Cristo, necessitou de um imenso sacrifício físico para serem "consagrados", todos envoltos em um suave e rígido véu do delírio.

\section{Conclusão}

Ao serem ressignificados em objetos artísticos, as obras de Bispo ficaram suscetíveis a mutações. Pollak afirma que a construção da auto -imagem não é isenta de mudança em função da transformação dos outros. Não obstante, para que fossem admitidos no universo artístico, os trabalhos de Bispo passaram por um crivo de

29 Segundo Walter Benjamin: "Na medida em que o valor de culto da imagem se seculariza, as noções de substrato da sua singularidade tomam-se mais indefinidas. Cada vez mais a singularidade da manifestação dominante na figura de culto é suplantada pela singularidade empírica do artista, ou da sua realização plástica, na concepção do observador" [BENJAMIN, op. cit., p. 226].

30 DANTO, Arthur. Após o fim da arte: a arte contemporânea e os limites da história. Tradução: Saulo Krieger. São Paulo: Odysseus Editora, 2006, p. 170-186. aceitabilidade, instituídos por um crítico e curador, a saber, Frederico Morais. Essa figura atuou como um representante que falou a linguagem da arte por ele, haja vista que nunca tenha se considerado artista ${ }^{31}$.

É inevitável que a absorção pelo sistema da arte faça com que os objetos de Bispo percam o significado mágico que possuía, com toda a aura mística que lhe era atribuída pelo autor as ressignificações sacras de seus objetos, as representações de seu próprio mundo. Assim, o inventário do universo perceptível de Bispo foi transformado, subdividido e rotulado em classificações artísticas: vitrines e acumulações; miniaturas e ORFAs; estandartes e panôs, entre outras tantas. Tal estratégia foi viável à época para que seus objetos fossem arquivados para posteriores exposições, e dessa forma, estariam livres de possíveis furtos por pacientes ou funcionários da Colônia - e salvos da iminente pilhagem.

Apesar de sua produção estar à margem da poética erudita e à margem da vida artística conceitual, Bispo deu vazão à sua subjetividade através de sua poíesis. Sob seus três pilares: construiu uma poesia oriunda de sua devoção religiosa, extraiu da riqueza visual da cultura nordestina seu valor simbólico e resistiu ao intenso sofrimento psíquico de sua doença e a partir dela - somado a obsessão em cumprir sua missão - construiu seu legado. A estética singular de seus trabalhos, então, seria a combinação de todos esses pilares em um ser. Talvez por essa complexidade, Bispo tenha levantado tantas questões pertinentes à arte - assim como, à psiquiatria, à psicologia e à sociologia.

Decerto, o campo artístico tenha abarcado este heterogêneo ser, pois como Bispo, à arte

31 "Convidado a ver suas peças no museu em 1982, [Bispo disse:] meus olhos não estão preparados para ver aquilo" [BARRETO FILHO, op. cit., p. 9] 
não compete uma simples definição. A arte contemporânea, como idéia geral, pôde abranger com toda propriedade, seus aspectos artísticos autoditadas, ricamente biográficos, assim como, pôde permitir a apropriação de um não -artista para o campo artístico. O que há de mais contemporâneo na arte, do que explorar os métodos apropriativos? Se Bispo aparentemente apropriou-se de sua memória e buscou ferramentas para cumprir a missão mais importante de sua vida, seus "trabalhos", de maneira análoga, foram usurpados à nomenclatura de "obra de arte". Entretanto, resumir a meras "obras" seria, no mínimo, depreciativo. Reaproprio seus trabalhos a um "acontecimento" - termo banalizado, mas que Jacques Derrida atribuía um significado místico, singular, arrebatador ${ }^{32}$-, que é o último elemento disparador da memória, a qual, neste caso, ficará imputada à nossa mente defender esse legado.

\section{Referências}

AQUINO, Ricardo. Uma imagem biografia. In: LAZARO, Wilson. Do Pitoresco ao Pontual. Rio de Janeiro: Réptil, 2012.

BARRETO FILHO, Waldir de Mello. A margem da poética. Disponível em: <http://periodicos. ufes.br/farol/article/view/11421> último acesso em 10/10/2017.

CAMPOS, Marcelo. Um canto dois sertões: Bispo do Rosário e os 90 anos da Colônia Juliano Moreira. Rio de Janeiro: MBrac, Azougue Editorial, 2016.

DERRIDA, Jacques. Pensar em não ver: escritos sobre a arte do visível. [org. Ginette Michaud,

32 "Um acontecimento é o que vem [...] isto é, um acontecimento diruptivo, inaugural, singular, na medida em que precisamente não pensamos vir." [DERRIDA, Jacques. Pensar em não ver: escritos sobre a arte do visível. [org. Ginette Michaud, Joana Masó e Javier Bassas] Tradução: Marcelo Jacques de Moraes. Florianópolis: Editora da UFSC, 2012, p. 70]
Joana Masó e Javier Bassas] Tradução: Marcelo Jacques de Moraes. Florianópolis: Editora da UFSC, 2012.

HIDALGO, Luciana. Arthur Bispo do Rosário: O Senhor do Labirinto. Edição Revista. Rio de Janeiro: Editora Rocco, 2011.

MORAIS, Frederico. A reconstrução do universo segundo Arthur Bispo do Rosário. In: Registros da minha passagem pela Terra: Arthur Bispo do Rosário, 17-25. Ex. cat., São Paulo, Brasil: Museu de Arte Contemporânea da Universidade de São Paulo, 1990.

___. Frederico. Arte Além da Loucura. [org. e prefécio Flávia Corpas) 1. Ed. Rio de Janeiro: NAU: Livre Galeria, 2013.

NOVELLO, Maria. Teoria da Arte em Platão: O Conceito de Poíesis. In: 6a Mostra Acadêmica UNIMEP, 2008.

POLLAK, Michael. Memória e Identidade Social. In: Estudos Históricos, Rio de Janeiro, vol. 2, n. 3, 1989.

\section{Ana de Almeida}

É artista-educadora, professora e pesquisadora. É mestre em Teoria e História da Arte pelo Programa de Pós-Graduação em Artes (PPGA) UFES) da Universidade Federal do Espírito Santo. Contato: ana.almeida.escritorio@gmail.com 